\title{
Aspectos socioambientais da proliferação de arboviroses na Região Metropolitana do Cariri, Ceará: A perspectiva dos Objetivos do Desenvolvimento Sustentável (ODS)
}

\section{Cícero dos Santos Leandro*, Francisco Bernardo de Barros, Priscilla Barbosa de Araújo Moreira, Lucas Fernandes dos Santos, Jeniffer de Nadae e Marcelo Martins de Moura-Fé}

Universidade Federal do Cariri. Campus Crato. Rua Icaro de Sousa Moreira. Muriti. Crato-CE, Brasil (CEP 63130-025).*E-mail: cicero.leandro2@gmail.com.

Resumo. Os objetivos do desenvolvimento sustentável (ODS) são resultantes de preocupações que surgiram a partir do século XX. O ODS 11 preocupa-se com o desenvolvimento de cidades inteligentes e está diretamente relacionado aos ODS 3 e 6, que visam a garantir à população, saúde, água potável e saneamento básico, respectivamente, visto que os problemas de urbanização podem afetar os serviços urbanos, interferindo dessa forma na saúde da população. Nessa perspectiva, com o presente trabalho objetivou-se verificar o papel dos aspectos ambientais urbanos na ocorrência de arboviroses (dengue, zika e chikungunya) transmitidas pelo Aedes aegypti no Crajubar (Crato, Juazeiro do Norte e Barbalha), sob a ótica dos ODS. A pesquisa deu-se a partir de consulta na literatura científica e plataformas oficiais sobre o processo de urbanização e saneamento, bem como dados dos boletins epidemiológicos do Estado do Ceará. Foi possível observar que a falta de cobertura de rede de esgoto teve uma forte correlação com a proliferação do A. aegypti. Para o quesito coleta de resíduos a correlação foi moderada. Em relação ao acesso a água, a correlação se mostrou menos acentuada em relação às variáveis analisadas. De modo geral, percebe-se que há uma estreita ligação entre a deficiência no saneamento básico e o aumento da proliferação do A. aegypti nos municípios estudados. Pode-se concluir que assegurar o controle e disseminação das arboviroses em questão pode contribuir para alcançar as metas dos ODS, garantindo o bem-estar e a saúde das atuais e futuras gerações.

Palavras-chave: Crajubar; Aedes aegypti; Urbanização; Saneamento.

Abstract. Socio-environmental aspects of the proliferation of arboviruses in the Metropolitan Region of Cariri, Ceará: The perspective of the Sustainable Development Goals (SDGs). The
Recebido

$28 / 01 / 2021$

Aceito

25/04/2021

Publicado

30/04/2021

Acesso aberto

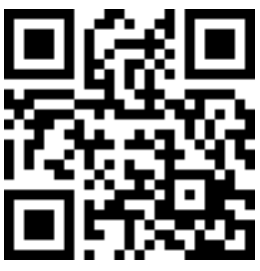

ORCID

D) 0000-0002-6311-1715

Cícero dos Santos

Leandro

(D) 0000-0001-8093-9920

Francisco Bernardo de Barros

D) 0000-0003-3983-4398

Priscilla Barbosa de Araújo Moreira

D) 0000-0002-6687-9017

Lucas Fernandes dos Santos 
objectives of sustainable development (SDGs) are the result of concerns that have emerged since the 20th century. The SDG 11 is concerned with the development of smart cities and is directly related to SDGs 3 and 6, which aim to guarantee to the population, health, drinking water, and basic sanitation, respectively, since urbanization problems can affect services urban, thereby interfering in the health of the population. In this perspective, the present study aimed to verify the role of urban environmental aspects in the occurrence of arboviruses (dengue, zika and chikungunya) transmitted by Aedes aegypti in Crajubar (Crato, Juazeiro do Norte and Barbalha), from the perspective of the SDGs. The research took place through consultation in the scientific literature and official platforms on the urbanization and sanitation process, as well as data from the epidemiological bulletins of the State of Ceará. It was possible to observe that the lack of sewage coverage had a strong correlation with the proliferation of $A$. aegypti. For the question of waste collection, the correlation was moderate. In relation to access to water, the correlation was less pronounced in relation to the variables analyzed. In general, it is clear that there is a close link between the deficiency in basic sanitation and the increase in the proliferation of $A$. aegypti in the cities studied. It can be concluded that ensuring the control and dissemination of the arboviruses in question can contribute to achieving the goals of the SDGs, guaranteeing the well-being and health of current and future generations.

Keywords: Crajubar; Aedes aegypti; Urbanization; Sanitation.
(D) $0000-0001-6352-8986$ Jeniffer de Nadae

(1) 0000-0002-0336-557X

Marcelo Martins de Moura-Fé

\section{Introdução}

O ser humano sempre manteve uma íntima relação com o meio ambiente, de maneira a atender suas mais diversas necessidades, sendo que ao longo do tempo esta relação foi se intensificando, o que gerou efeitos positivos e negativos para o meio ambiente (Correia e Dias, 2017).

A partir da segunda metade do século $\mathrm{XX}$, as preocupações de estudiosos e representantes das nações sobre a exploração do meio ambiente pelo ser humano e o futuro da humanidade, culminaram em reuniões e publicações que visavam conscientizar as nações para as consequências no futuro, das ações humanas no meio ambiente (Vianna, 2015). A Conferência de Estocolmo em 1972, o relatório "Nosso Futuro Comum" (Our Common Future) pela Comissão Brundtland, e a Eco'92, ou Rio'92, são reflexos destas preocupações (Sachs, 2012).

Ações mais efetivas puderam ser observadas no início do século XXI com a publicação dos oito Objetivos de Desenvolvimento do Milênio - ODM (Nascimento e Chacon, 2016) e posteriormente com a publicação do documento "Transformando o nosso mundo: a agenda 2030 para o desenvolvimento sustentável” (UNDP, 2016), onde são apresentados os 17 Objetivos de Desenvolvimento Sustentável (ODS). Estas iniciativas foram encabeçadas pela Organização das Nações Unidas (ONU) em parceria com os Estados-Membros, no intuito de direcionar o desenvolvimento sustentável das nações filiadas (Sena et al., 2016). 
No contexto desta pesquisa, destaca-se que o ODS-3 visa garantir a saúde de qualidade e bem-estar para todas as populações; o ODS-6 tem por objetivo garantir a disponibilidade de água potável e saneamento básico para todos; enquanto que o ODS-11 dá ênfase ao desenvolvimento de cidades sustentáveis (ONU, 2020). Estes três objetivos possuem metas relacionadas com a universalização do saneamento básico, disponibilidade de água potável e a gestão de resíduos sólidos nos países. Estas metas são importantes, pois os aspectos relacionados ao meio ambiente influenciam na questão da saúde pública, de forma que os problemas associados às questões ambientais estão diretamente ligados com a proliferação de doenças no Brasil (Gouveia, 1999).

Nos municípios brasileiros esses problemas são bem evidentes, pois a sua ampla maioria surgiu e desenvolveu-se sem planejamento urbano, e a infraestrutura não é adequada para o rápido crescimento populacional (Almeida et al., 2020). Outrossim, esses fatores contribuem para o fato do Brasil ser historicamente afetado por doenças infectocontagiosas, provocadas por arbovírus ao longo das últimas décadas, principalmente dengue, zika e chikungunya, que são veiculadas majoritariamente pelo mosquito vetor Aedes aegypti (Linnaeus, 1762), e apresentam alta prevalência em áreas urbanas (Almeida et al., 2020).

No Brasil, somente no ano de 2019 foram notificados 1.544 .987 casos de dengue no país. No que se refere à chikungunya e à zika foram registrados 132.205 e 10.768 de casos, respectivamente (Brasil, 2020a). Em contrapartida, dados da Agência Nacional de Águas e Saneamento Básico (ANA, 2020) revelam que o Brasil precisa melhorar muito no abastecimento de água tratada, e na coleta e tratamento de esgoto urbano. Estes aspectos são relevantes pois, segundo Almeida et al. (2020), existe uma íntima relação entre estes serviços predominantemente urbanos e a proliferação do A. aegypti.

Esta realidade pode ser observada nos municípios que compõem o Crajubar. Localizado no Cariri Cearense, ao sul do Estado do Ceará, o Crajubar, bloco composto pelos Municípios de Crato, Juazeiro do Norte e Barbalha, compreende a porção mais desenvolvida da Região Metropolitana do Cariri (RMCariri) (Ceará, 2020a).

Fatores como, fácil acesso do bloco às principais capitais do Nordeste e o turismo ecológico e religioso proporcionados pela Chapada do Araripe e a figura mítica do Padre Cícero podem ser apontados como responsáveis pelo rápido crescimento do bloco (Pereira e Cardoso, 2020). Crescimento este que atrai a vinda de pessoas que buscam melhores condições socioeconômicas, o que explica a grande população dos três municípios, que segundo dados do IBGE (2020), somadas, é estimada para 2020 em 470.523 habitantes, sendo que a maior parte reside na zona urbana (IBGE, 2010).

No entanto, mesmo com o notório desenvolvimento, dados do Instituto de Pesquisa e Estratégia Econômica do Ceará (IPECE, 2018a, 2018b, 2018c), revelam que, apesar dos serviços urbanos no Crajubar apresentarem melhores índices do que em outros municípios da região, ainda é preciso melhorar na coleta de esgoto, medida fundamental no combate às doenças transmitidas pelo A. aegypti, que tem provocado graves prejuízos ao Crajubar.

Somente nos últimos dois anos foram notificados 1.999 casos de dengue. Em 2020, até a semana epidemiológica (SE) 39 foram notificados 2.811 casos, com 3 óbitos. Chikungunya e Zika, somam entre 2018 e 2019, 223 e 25 casos, respectivamente (Ceará, 2019), esses dados reforçam a ideia de que o crescimento urbano e o desenvolvimento nem sempre ocorrem de maneira sustentável.

Face ao exposto, este trabalho busca verificar o papel dos aspectos ambientais urbanos na ocorrência de arboviroses transmitidas pelo $A$. aegypti no Crajubar (Crato, Juazeiro do Norte e Barbalha), sob a ótica dos ODS-03, 06 e 11 nos núcleos urbanos dos municípios que compõem o triângulo Crajubar, na RMCariri, Ceará. 


\section{Material e métodos}

A Região Metropolitana do Cariri, localizada ao sul do Estado do Ceará, contempla nove municípios, Crato, Juazeiro do Norte e Barbalha, que são considerados os principais municípios, formando o chamado "Crajubar", além de Jardim, Missão Velha, Caririaçu, Farias Brito, Nova Olinda e Santana do Cariri (Figura 1). A região abrange área com cerca de $5.465,86 \mathrm{~km}^{2}$ e uma população residente, estimada em 2020, de 612.956 habitantes (IBGE, 2020).

0 estudo realizado consistiu em uma pesquisa documental sobre a relação entre o processo de urbanização e saneamento com a incidência das arboviroses (dengue, zika e chikungunya) no Crajubar.

Utilizou-se como fonte de dados os boletins epidemiológicos divulgados pela Secretaria Estadual de Saúde do Ceará e informações coletadas no site do Instituto de Pesquisa Econômica Aplicada do Ceará (IPECE), do Sistema Nacional de Informações sobre Saneamento (SNIS), além de outros documentos, tais como os divulgados pelo Ministério da Saúde, pela Agência Nacional de Águas e Saneamento Básico (ANA) e pelo Instituto Brasileiro de Geografia e Estatística (IBGE).

A correlação entre as questões ambientais urbanas e a ocorrência de arboviroses transmitidas pelo $A$. aegypti foi analisada pelo teste de coeficiente de correlação de Pearson, com nível e significância de 5\%, através do programa Bioestat 5.3. Os números expressos foram tabulados e representados em gráficos e tabelas, utilizando os softwares GraphPad Prism 6.0 e Word, respectivamente.

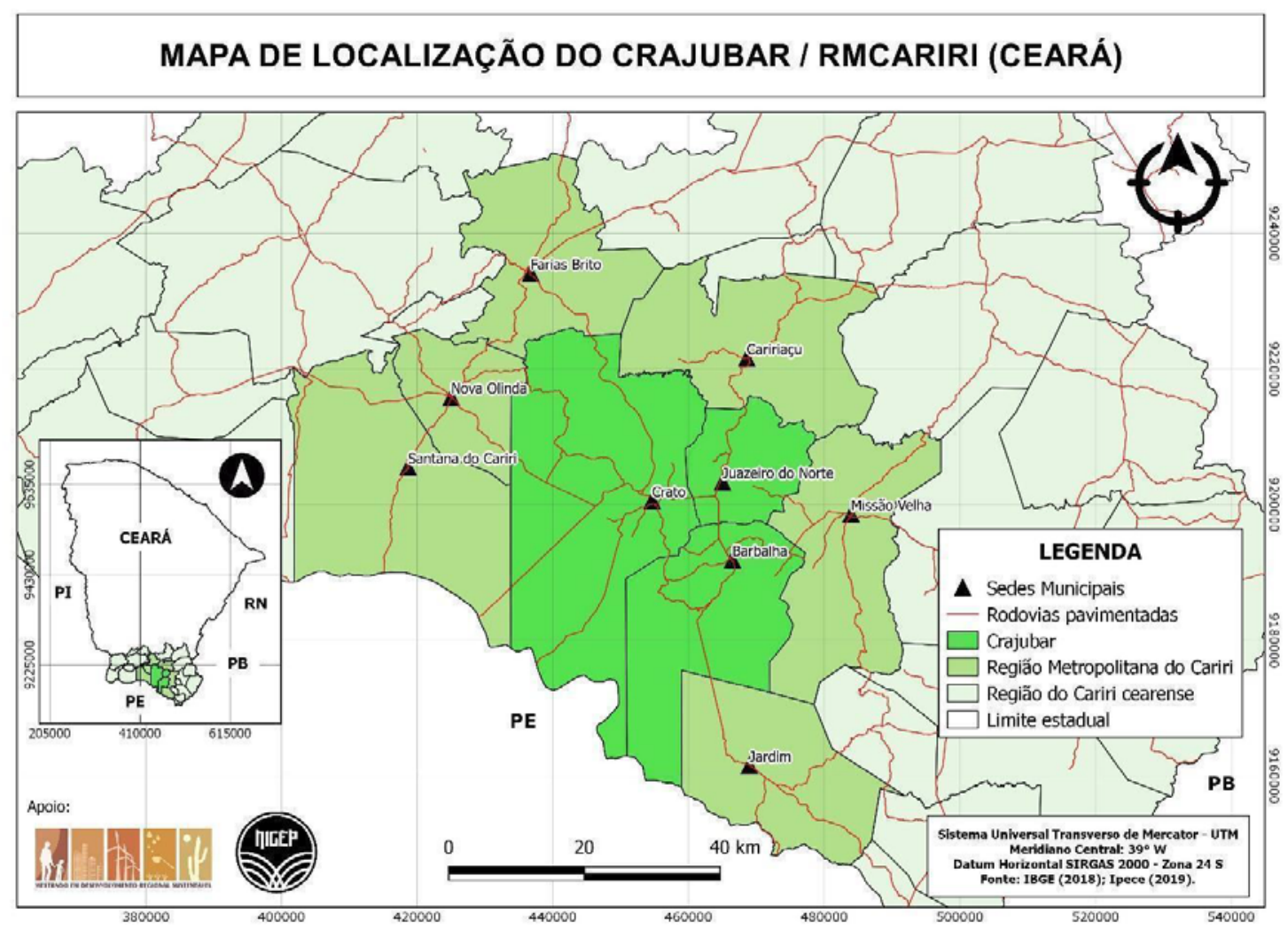

Figura 1. Mapa de localização da área de estudo. Fonte: IBGE (2018); IPECE (2019). 


\section{Resultados e discussão}

\section{Meio ambiente, saúde e os Objetivos do Desenvolvimento Sustentável (ODS)}

Numa abordagem ampla, o conceito de desenvolvimento sustentável resulta da compreensão de que existe um vínculo global entre questões ambientais e socioeconômicas vinculadas à pobreza, desigualdade e preocupações com a qualidade de vida das próximas gerações (Hopwood et al., 2005). Portanto, avaliar problemas de sustentabilidade envolve a inter-relação dos sistemas ecológicos aos sociais, exigindo soluções integradas (UNSDSN, 2016).

No plano da Agenda 2030 estão inseridos os 17 Objetivos do Desenvolvimento Sustentável (ODS) e suas 169 metas integradas, indivisíveis e equilibradas nos aspectos ambiental, social, econômico e institucional. Alicerçados pelo legado dos Objetivos de Desenvolvimento do Milênio (ODM), traz planos e ações para os próximos 10 anos na busca de um mundo sustentável (UNSDSN, 2016).

A Saúde, Objetivo 3, na agenda 2030, revela sua interligação com os problemas de saneamento e água potável (Objetivo 6) e com municípios e comunidades sustentáveis (Objetivo 11). Deve-se ter em mente que todos os ODS são produtos do território sociogeográfico e que o alcance das suas metas dependerá da integração do local com o global (Djonú et al., 2018).

De um modo geral, o Objetivo 3 busca assegurar uma vida saudável e promover o bem-estar para todos, em todas as idades. Considerando a sua contribuição para o crescimento econômico da sociedade, a saúde é vista como um importante indicador do progresso de nações no alcance ao Desenvolvimento Sustentável (Fairall e Bateman, 2017). A promoção da saúde, em todas as idades, insere benefícios que se estendem através das gerações. Desse modo, a inserção da saúde como um dos ODS traz o reconhecimento de ser um elemento-chave ao desenvolvimento humano, com vastos e multidimensionais determinantes sociais (Djonú et al., 2018). Portanto, a erradicação das doenças negligenciadas endêmicas numa determinada região, nas quais se enquadram as arboviroses transmitidas pelo A. aegypti, bem como a redução da incidência dessas, são ações fundamentais para assegurar uma vida saudável e o bem-estar da população (IPEA, 2018).

O Objetivo 6 trata-se de assegurar a disponibilidade e gestão sustentável da água e saneamento para todos. Existe na literatura uma extensa relação entre água, saneamento e saúde (e.g., Gundry et al., 2004; Moe e Rheingans, 2006; Bartram e Cairncross, 2010). A universalização do serviço de abastecimento de água e saneamento para todos não é uma realidade no Brasil. Portanto, medidas identificadas nos ODS, como promover o alcance universal e equitativo à água potável, segura e acessível; ao saneamento e higiene adequados e equitativos para todos; reduzir a poluição; reduzir à metade a proporção de águas residuais não tratadas; assegurar o abastecimento de água doce, ampliar a cooperação e o apoio à capacitação em atividades e programas relacionados à água e saneamento, incluindo a coleta de água, a eficiência no uso da água e o tratamento de efluentes; apoiar e fortalecer a participação das comunidades locais para melhorar a gestão da água e do saneamento, são ações importantes e indispensáveis para melhorar a qualidade de vida e bem-estar humano da população, ao tempo em que diminui os focos onde mosquitos vetores de doenças possam se estabelecer (IPEA, 2018).

Para Oliveira Júnior (2018), a disponibilidade de água potável é um fator indispensável para o bem-estar e saúde da população, visto que há um decréscimo na ocorrência de doenças por veiculação hídrica ao passo que se tem uma maior eficiência nos serviços de abastecimento.

O Objetivo 11 traz ações para tornar os municípios e os assentamentos humanos inclusivos, seguros, resistentes e sustentáveis. A qualidade do ambiente onde as pessoas residem têm efeitos significativos na saúde (Kjellstrom et al., 2007). 
No caso brasileiro, os problemas socioambientais são causados por ações de expansão urbana, especulação imobiliária, déficit habitacional, periferização, metropolização, ausência de planejamento e gestão urbana-regional eficientes e políticas públicas deficitárias no sentido de garantir uma melhor distribuição socioespacial de recursos urbanos no território (Araújo e Pessoa, 2019).

Assim, assegurar que até 2030 as metas deste objetivo sejam alcançadas, requer um grande esforço coordenado dos governos em todos seus níveis (Sena et al., 2016). Metas como aumentar a urbanização inclusiva e sustentável e reduzir o impacto ambiental negativo per capita dos municípios, inclusive prestando especial atenção à qualidade do ar e a gestão de resíduos municipais (IPEA, 2018), podem ser fundamentais na redução do número de mortes e de pessoas afetadas por doenças transmitidas por vetores.

\section{Urbanização e saneamento na ocorrência de doenças vetoriais}

As Nações Unidas (UN, 2018) descreve a urbanização como um processo socioeconômico complexo que modifica o ambiente construído, transformando áreas rurais em urbanas, ao mesmo tempo que muda o arranjo espacial de uma população da zona rural para a urbana. A UN (2018) indicava ainda que $55 \%$ da população mundial reside no meio urbano e estima-se para 2050 um aumento de $68 \%$ da população mundial urbana.

De acordo com Mendonça et al. (2009), o processo de urbanização, associado ao desenvolvimento dos municípios, sempre esteve ligado diretamente às condições de saúde e meio ambiente, já que esses movimentos propiciam condições para o desenvolvimento e proliferação de vetores e de doenças contagiosas, contribuindo para o surgimento de surtos, epidemias e pandemias em todo o mundo.

A Organização Mundial de Saúde (WHO, 2008) afirma que o processo de urbanização tem crescido em ritmo acelerado, e o crescimento desordenado é uma realidade vivida basicamente por todo o mundo.

A urbanização não planejada, associada a padrões de consumo e produção não sustentáveis, com a incapacidade do poder público em gerenciar o processo de urbanização, traz prejuízos à sustentabilidade devido à expansão urbana, poluição e degradação ambiental (UN, 2018).

Os processos de urbanização dos municípios vêm sofrendo alterações climáticas, como o aumento da temperatura, a baixa umidade relativa e a mudança na direção dos ventos. Essa modificação do clima no ambiente influencia diretamente na qualidade de vida da população (Lima Júnior, 2018).

Para Almeida et al. (2020), a urbanização no Brasil ocorreu de forma desordenada, sem planejamento adequado, gerando problemas como falta de abastecimento de água, esgotamento sanitário e ocupações irregulares trazendo sérios riscos de contaminações por doenças de veiculação hídrica.

Para Moreira (2015), os serviços de saneamento básico são fundamentais para promoção da qualidade de vida e dignidade da população. Borja (2014) afirma que a questão do saneamento básico no Brasil ainda é um grande desafio para os governantes, o serviço precário e os déficits denunciam o atraso do país na garantia de direitos básicos como acesso à água e ao destino seguro dos dejetos e resíduos sólidos.

De acordo com a publicação sobre o Panorama de Saneamento do Brasil, divulgados pela Agência Nacional de Águas e Saneamento Básico (ANA, 2020), com base nos dados do Sistema Nacional de Informações sobre Saneamento (SNIS) referentes ao ano de 2018, no Brasil ainda há uma relevante carência no que diz respeito aos serviços de saneamento básico, como indicam os dados abaixo:

- $83,6 \%$ da população conta com abastecimento de água;

- $53,2 \%$ da população dispõe de coleta de esgoto; 
- $46,3 \%$ da população é atendida com tratamento de esgoto, e;

- $98,8 \%$ da população urbana possui serviço de coleta de resíduos domiciliares.

Segundo o IBGE (2019), as regiões norte e nordeste foram responsáveis pela menor cobertura de esgotamento sanitário do país, registrando taxas de 21,8\% e 44,6\%, respectivamente. Quanto ao abastecimento de água, o Nordeste atingiu uma cobertura de acesso diário a água de 69,1\% dos domicílios, enquanto que cerca de 12 milhões de pessoas não possuem acesso diário à água na região. No que tange a coleta de lixo, cerca de 10,5 milhões de moradores da região nordeste não contam com acesso aos serviços de coleta de lixo.

Conforme descrito no Relatório de Fiscalização da Agência Reguladora do Estado do Ceará (ARCE, 2020), no município de Barbalha (Figura 2) o índice de cobertura de água e esgoto em janeiro de 2020 é de 99,39\% e 46,65\%, respectivamente. Já para o serviço de coleta de resíduos o município possui uma cobertura de 71,02\% (IPECE, 2018a).

Para o Município de Crato (Figura 2), 97,26\% da população urbana conta com cobertura de água, $32,75 \%$ dos munícipes são atendidos com cobertura de esgoto e 84,12\% possui serviço de coleta de resíduos urbanos (IPECE, 2018b). Já em relação ao Município de Juazeiro do Norte (Figura 2) 99,07\% da população urbana é contemplada pelo serviço de abastecimento de água, 36,42\% contam com cobertura de esgotamento sanitário e 94,22\% da população dispõe de serviço de coleta de lixo (IPECE, 2018c).

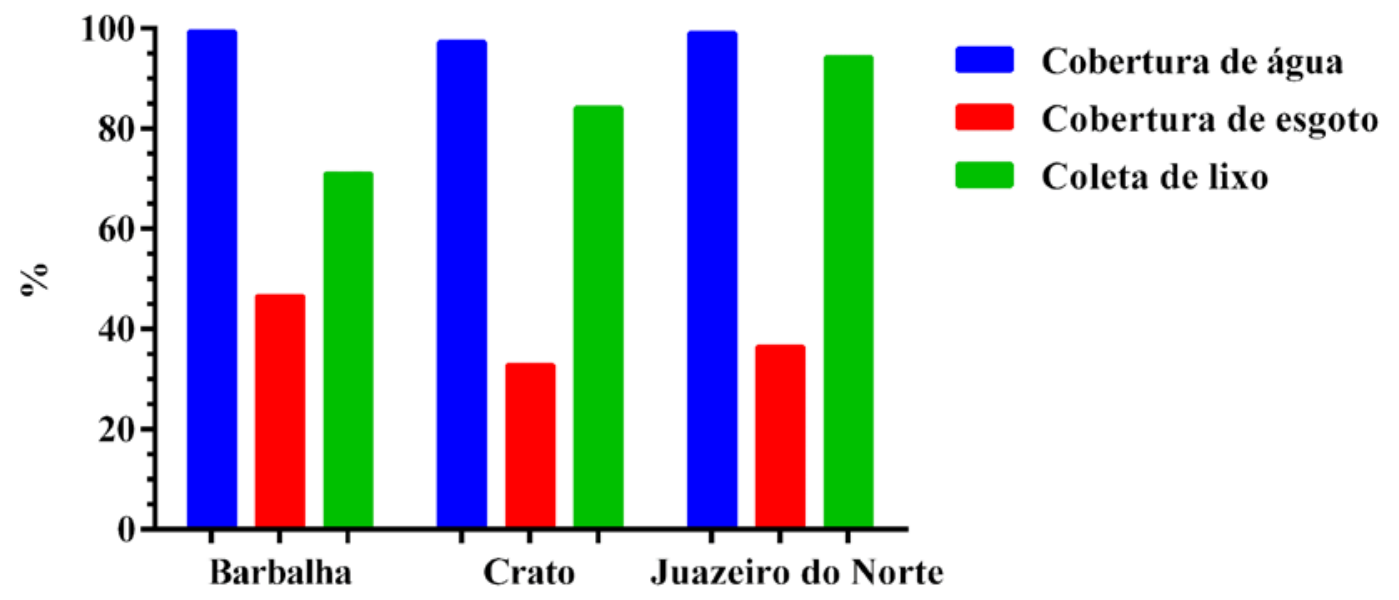

Figura 2. Índices de cobertura dos serviços de saneamento básico na região Crajubar.

Heller (1997) enfatiza que diversas doenças relacionadas com a ausência ou ineficiência de saneamento básico são encontradas, principalmente, em países em desenvolvimento, outrora chamados de terceiro mundo. As principais doenças relacionadas com a falta de saneamento básico adequado são a febre tifoide, febre paratifoide, poliomielite, hepatite a, leptospirose, esquistossomose, difilobotríase, filariose, malária arboviroses, febre amarela, dengue, chikungunya e zika (FUNASA, 2010).

Os arbovírus são uma causa de preocupação para a saúde pública, com impactos clínicos, econômicos e sociais, seu controle representa um desafio, principalmente no 
Brasil. As arboviroses de maior circulação no território brasileiro são as da dengue, zika e chikungunya, devido às condições ambientais proporcionadas (Gusmão et al., 2019).

Rossetto et al. (2017) reforçam que as condições climáticas, a diversidade de ecossistemas brasileiros, a urbanização, a grande mobilidade por todo o país, a crise econômica e o impacto gerado na infraestrutura no controle vetorial e, sobretudo, nos demais programas de saúde pública, foram de suma importância para o controle do surto atual dos Zika vírus, chikungunya e febre amarela.

Diniz et al. (2019) afirmam ainda que as doenças relacionadas ao saneamento não estão associadas apenas ao consumo de água, mas também aos vetores que nela se reproduzem como as arboviroses dengue, chikungunya e zika que são transmitidas pelo mosquito $A$. aegypti e possuem sintomas semelhantes.

A reprodução do mosquito é favorecida em regiões urbanas cujos locais contém poças de água parada e o acúmulo de lixo (Almeida et al., 2020), bem como as condições ambientais e climáticas que favorecem a proliferação desses vetores, trazendo riscos de contaminação as populações residentes no entorno destes locais (Lima Júnior, 2018). Vale ressaltar que a destinação incorreta dos resíduos sólidos em terrenos baldios, vias públicas e rios, também é um dos principais agravos para a proliferação do A. aegypti conforme mencionado por Zanon (2018).

\section{Ocorrência de arboviroses transmitidas pelo $A$. aegypti no Crajubar}

0 mosquito A. aegypti é o principal vetor responsável por transmitir vírus causadores de arboviroses de importância para a saúde pública, principalmente em países tropicais e subtropicais como o Brasil (Fernandez et al., 2020). A destruição dos hábitats naturais ocasionados pela ação antrópica levou parte da população silvestre do mosquito a sofrer pressões seletivas que pode ter sido responsável pela disseminação e adaptação da espécie em meio aos humanos (Zara et al., 2016).

A dengue, principal arbovirose em termos epidemiológicos, é causada por um vírus da Família Flaviviridae, do gênero Flavivirus, com quatro sorotipos conhecidos (DENV-1, DENV-2, DENV-3 e DENV-4), que são transmitidos ao homem pela picada da fêmea do mosquito A. aegypti. Há uma estimativa de que anualmente ocorram cerca de 400 milhões de infecções de dengue, onde aproximadamente 96 milhões dessas se manifestam clinicamente (Yang et al., 2020; Wilder-Smith et al., 2019). De acordo com a Organização Mundial de Saúde (WHO, 2012), a doença pode se diferenciar em três tipos, (i) dengue, (ii) dengue com sinais de alarme, e (iii) dengue grave.

Segundo Martins (2020), o histórico da dengue no Brasil inicia-se em 1845, com o surgimento da primeira epidemia registrada no estado do Rio de Janeiro e, provavelmente se deu pela chegada de navios negreiros que trouxeram pessoas infectadas com o vírus da dengue e da febre amarela, juntamente com o vetor. Nos anos seguintes o vírus reapareceu e não só os municípios do estado do Rio de Janeiro foram atingidos pelos inúmeros casos, mas outros municípios distribuídos nas regiões Sudeste e Nordeste do Brasil (Teixeira e Barreto, 1996). Esses autores ainda afirmam que outros estados tiveram um cenário epidemiológico bem semelhante ao do Rio de Janeiro, como foi o caso de Alagoas, Bahia, Ceará, Pernambuco e Minas Gerais, que juntos somaram mais de 40 mil casos confirmados.

Segundo Teixeira et al. (1999), com o passar do tempo e após algumas epidemias, a dengue se disseminou por todo país, sendo o Nordeste uma das regiões com elevados coeficientes de incidência e com registros de sucessivas epidemias (Martins, 2020).

No Brasil, até a semana epidemiológica no 36 de 2020, foram notificados 928.282 casos prováveis de dengue, com taxa de incidência de 441,7 casos por 100 mil habitantes no país. Neste mesmo período, a região Nordeste notificou 140.527 casos prováveis, com incidência de 246,2/100 mil habitantes e no Estado do Ceará foram constatados 22.167 e incidência 242,7/100 mil habitantes (Brasil, 2020b). 
A primeira epidemia de dengue do Estado do Ceará foi registrada em 1986, a partir de então os quatro sorotipos já foram isolados, com dinâmica de introdução da seguinte forma, DENV-1 (1984), DENV-2 (1994), DENV-3 (ano de 2002) e por último, o DENV-4, introduzido em 2011 (Ceará, 2019). Desde o aparecimento da dengue até o ano de 2016, o Ceará passou por 14 epidemias ocorridas nos anos de 1987, 1994, 2001, 2003, 2005, 2006, 2007, 2008, 2011, 2012, 2013, 2014, 2015 e 2016, todas com incidência maior que 300 casos $/ 100$ mil habitantes (Cavalcanti et al., 2018).

Nas últimas décadas percebeu-se uma forte disseminação do A. aegypti no Estado do Ceará. Em 2019, 100\% do território cearense registrou a presença do A. aegypti, destes, 1,63\% (3/184) dos municípios apresentaram alta infestação. Em situação de média infestação encontram-se 17,39\% (32/184) e 80,98\% (149/184) demonstraram índice de infestação satisfatório. Os focos do A. aegypti predominaram nos depósitos localizados ao nível do solo (tais como, cisterna, tambor e tanque) 60,34\%, seguidos pelos depósitos móveis (vasos ou pratos de plantas, bebedouros de animais etc.) com 21,94\%. Os demais $(17,72 \%)$, como caixa d'água, pneus, calhas e recipientes plásticos descartados, tiveram menor nível de infestação (Ceará, 2019).

Foi confirmada em 2015 a transmissão autóctone dos vírus causadores da chikungunya (CHIKV) e zika (ZIKV) no estado do Ceará, aumentando as preocupações com o mosquito A. aegypti (Ceará, 2019).

0 vírus que causa a chikungunya pertence à Família Togaviridae, sendo transmitido principalmente por fêmeas de mosquitos $A$. aegypti, com os primeiros registros no Brasil em setembro de 2014 (Honório et al., 2015). Os sintomas mais comuns da doença na fase aguda é uma febre alta acompanhada de artralgias e erupção cutânea. Após a fase aguda alguns pacientes podem apresentar persistência das artralgias por semanas ou até anos, caracterizando a fase crônica da doença (Torii et al., 2020). A doença pode apresentar um período de até 10 dias de viremia no hospedeiro, esse período tem início aproximadamente dois dias antes do início dos sintomas (Donalisio e Freitas, 2015).

No que diz respeito aos dados da chikungunya, até a semana epidemiológica 36 de 2020 foram notificados 69.702 casos prováveis no país, com incidência de 33,2/100 mil habitantes. A região Nordeste apresentou 48.084 casos prováveis, a maior taxa de incidência dentre as demais regiões, com 84,3/100 mil habitantes e no Ceará foram 1.009 casos prováveis, com incidência de 11,0/100 mil habitantes (Brasil, 2020b).

Outra arbovirose de caráter importante é a zika, que teve o primeiro registro no Brasil no ano de 2015 (Campos et al., 2015; Lowe et al., 2018), causada por um vírus que pertence à Família Flaviridae. 0 Zika vírus é transmitido aos seres humanos principalmente pela picada de fêmeas de A. aegypti infectadas (Boyer et al., 2018). A maioria dos infectados pelo vírus são assintomáticos ou desenvolvem apenas sintomas leves da doença, como febre, cefaléia, mialgia, erupção cutânea, dores nas articulações e conjuntivite (Ndeffo-Mbah et al., 2016). Apesar de a doença ser muitas vezes autolimitada, a infecção pelo vírus em fetos tem sido associada ao desenvolvimento de doenças congênitas, incluindo a microcefalia e doenças neurológicas como a síndrome de GuillainBarré (Cao-Lormeau et al., 2016).

Em relação aos dados epidemiológicos da zika, até a semana epidemiológica 36 de 2020, foram notificados 6.220 casos prováveis com taxa de incidência de 3.0/100 mil habitantes no país. 0 nordeste teve 4.442 casos prováveis e também foi a região com maior incidência, com 7.8 casos/100 mil habitantes e no Ceará registrou-se 174 casos prováveis e incidência de 1,9/100 mil habitantes (Brasil, 2020b).

Dados da semana epidemiológica 44 revelam que de 2019 para 2020 houve um aumento de 3.786 para 7.585 dos casos de dengue nas superintendências do Cariri de 100,5\%, onde o Crato foi o município com maior incidência, com 1.522 desses casos. Neste mesmo período foram registrados dois óbitos pela doença em Juazeiro do Norte e um óbito em Barbalha (Ceará, 2020c). 
Em relação ao controle das arboviroses, o Crajubar apresenta baixos índices de visitas de controle vetorial, a exemplo de Juazeiro do Norte onde apenas $20,46 \%$ das residências do município é coberta pelas visitas dos Agentes de Combate às Endemias. Isso somado ao fato do Crajubar ser composto por municípios que recebe um grande número de visitantes anualmente, torna difícil o controle das arboviroses (Barreto, 2020).

Conforme a Tabela 1, nota-se que até a semana epidemiológica 36 de 2020, os maiores números de casos confirmados de dengue foram registrados no Município de Crato (1.300), seguidos por Juazeiro (1.208) e Barbalha (417). Em relação à chikungunya, foram sete casos confirmados em Barbalha e dois para o Crato, enquanto que Juazeiro do Norte não registrou nenhum. Já para zika, o Crato foi o único que registrou essa arbovirose, com um caso confirmado (Ceará, 2020b).

Tabela 1. Distribuição epidemiológica dos casos de arboviroses no Crajubar referentes às semanas epidemiológicas 1 a 36 (29/12/2019 a 10/09/2020).

\begin{tabular}{|c|c|c|}
\hline $\begin{array}{l}\text { Arboviroses } \\
\text { (Crato), 2020 }\end{array}$ & \multicolumn{2}{|c|}{ Registro de casos } \\
\hline \multirow{2}{*}{ Dengue } & Casos notificados & 1.938 \\
\hline & Casos confirmados & 1.300 \\
\hline \multirow{2}{*}{ Chikungunya } & Casos notificados & 6 \\
\hline & Casos confirmados & 2 \\
\hline \multirow{2}{*}{ Zika } & Casos notificados & 8 \\
\hline & Casos confirmados & 1 \\
\hline $\begin{array}{c}\text { Arboviroses } \\
\text { (Juazeiro do Norte), } 2020\end{array}$ & \multicolumn{2}{|c|}{ Registro de casos } \\
\hline \multirow{2}{*}{ Dengue } & Casos notificados & 1.712 \\
\hline & Casos confirmados & 1.208 \\
\hline \multirow{2}{*}{ Chikungunya } & Casos notificados & 8 \\
\hline & Casos confirmados & 0 \\
\hline \multirow{2}{*}{ Zika } & Casos notificados & 9 \\
\hline & Casos confirmados & 0 \\
\hline $\begin{array}{c}\text { Arboviroses } \\
\text { (Barbalha), } 2020\end{array}$ & \multicolumn{2}{|c|}{ Registro de casos } \\
\hline \multirow{2}{*}{ Dengue } & Casos notificados & 886 \\
\hline & Casos confirmados & 417 \\
\hline \multirow{2}{*}{ Chikungunya } & Casos notificados & 33 \\
\hline & Casos confirmados & 7 \\
\hline \multirow{2}{*}{ Zika } & Casos notificados & 27 \\
\hline & Casos confirmados & 0 \\
\hline
\end{tabular}

Fonte: Ministério da Saúde (2020b).

Conforme os dados do saneamento básico apresentados a seguir na Tabela 2, apesar de boa cobertura no abastecimento de água e razoável cobertura na coleta de lixo, para o quesito cobertura de esgoto foram encontrados baixos índices para o Crajubar, com $32,75 \%$ e $36,42 \%$ e $46,65 \%$ nos municípios de Crato, Juazeiro do Norte e Barbalha, respectivamente. 
Tabela 2. Correlação dos parâmetros ambientais do Crajubar ao índice de arboviroses registrados até a semana epidemiológica 36 de 2020.

\begin{tabular}{|l|c|c|c|c|}
\hline & Crato & Juazeiro do norte & Barbalha & $(\boldsymbol{r})$ \\
\hline Cobertura de água & $97,26 \%$ & $99,07 \%$ & $99,39 \%$ & 0.37 \\
\hline Coleta de lixo & $84,12 \%$ & $94,22 \%$ & $71,02 \%$ & 0.82 \\
\hline Cobertura de esgoto & $32,75 \%$ & $36,42 \%$ & $46,65 \%$ & -026 \\
\hline Índice de arboviroses & $1.483,6 \%$ & $635,1 \%$ & $1.572,6 \%$ & - \\
\hline
\end{tabular}

Fonte: IPECE (2018); Ministério da Saúde (2020b). (r) Coeficiente de correlação de Pearson.

A falta de abastecimento de água promove condições favoráveis para a proliferação do A. aegypti, uma vez que falta ou intermitência de água leva a população a utilizar caixas d'água, potes e barris. Esses recipientes sem tampas ou mal tampados, podem se tornar locais ideais para reprodução do mosquito (Silva e Machado, 2018), no entanto, no que diz respeito à cobertura de água no Crajubar, não foi observada uma correlação direta na incidência das arboviroses estudadas, visto que o coeficiente de correlação de Pearson $(r$ ) foi de 0,37 (Tabela 2).

O descarte de materiais como metais, vidro e plástico, são locais adequados para acúmulo de água e alimentos, ideais para a proliferação de agentes infecciosos (San Pedro et al., 2009; Elmec et al., 2016). Para esse quesito, nosso estudo revelou que a coleta de resíduos sólidos apresentou uma correlação moderada $(r=0.82)$ (Tabela 2).

Ainda observando a Tabela 2, observa-se que a falta de cobertura de esgoto apresentou significativa correlação negativa $(r=-0,26)$, o que pode indicar que dentre os demais aspectos analisados, este fator teve grande influência no índice de arboviroses. Silva (2007) e Gil et al. (2015) verificaram a proliferação de A. aegypti em fossas sépticas de esgoto. Esses autores apontam que isso é indicativo de um problema de saúde pública, uma vez que esses mosquitos podem ter se adaptado a um novo ambiente, com tolerância à água turva, rica em material orgânico em decomposição e sais.

\section{Considerações finais}

O estudo mostrou que os três municípios estudados possuem uma taxa superior a 97\% para acesso à água, mas ainda são bem deficitárias em coleta e tratamento de esgotos, precisando melhorar também a coleta de resíduos.

Observa-se que a falta de cobertura de rede de esgoto teve uma correlação direta com o desenvolvimento do A. aegypti, principal vetor causador das arboviroses. Reforçando essa análise, observou-se que no Crato, onde se tem a menor cobertura de coleta e tratamento de esgotos para os três municípios analisados, foi registrado o maior número de casos confirmados de dengue e zika em relação aos outros dois municípios. Para a questão de coleta de resíduos a correlação foi moderada, e no acesso a água a correlação não se intensificou em relação entre as variáveis analisadas.

Verificou-se ainda que a arbovirose de maior incidência na região Crajubar no ano de 2020 foi a dengue, sendo Crato o município com maior número de casos, seguido por Juazeiro do Norte e Barbalha. Foram registrados casos de zika e chikungunya, mas em números bem baixos.

Assim, percebe-se uma estreita ligação entre o saneamento básico e a proliferação de vetores como o A. aegypti, transmissor de diversas doenças que assola a população brasileira há muito tempo, observando-se uma carência na região Crajubar, sobretudo na coleta e tratamento de esgotos. 
Embora os dados desta pesquisa não possam assumir que as arboviroses estudadas são consequências exclusivamente das precárias condições de saneamento do Crajubar, os resultados não excluem sua importância na redução de tais doenças. Lembrando que são diversos os fatores socioambientais que não puderam ser pontuados nesta pesquisa, sejam pela ausência de dados ou pela dificuldade em seu acesso.

Contudo, pode-se concluir que existe uma fragilidade no sistema de saneamento nos municípios estudadas, necessitando de um olhar holístico que vise, de forma integrada, a alguns dos Objetivos do Desenvolvimento Sustentável - Objetivo 3 (Saúde e bem-estar), Objetivo 6 (Saneamento) e Objetivo 11 (Cidades e comunidades sustentáveis). Portanto, planos de governo necessitam inserir essa lógica - integrar esses objetivos - para o alcance de um controle sustentável para tais arboviroses e melhoria da qualidade de vida da população.

Conhecer o perfil sanitário dos Municípios de Crato, Juazeiro do Norte e Barbalha contribuirá para alcançar as metas dos Objetivos do Desenvolvimento Sustentável 3, 6 e 11, garantindo o bem-estar e saúde das atuais e futuras gerações.

\section{Conflito de interesses}

Os autores declaram não haver conflito de interesses.

\section{Referências}

Almeida, L. S.; Cota, A. L. S.; Rodrigues, D. F. Saneamento, arboviroses e determinantes ambientais: impactos na saúde urbana. Ciência \& Saúde Coletiva, v. 25, n. 10, p. 38573868, 2020. https://doi.org/10.1590/1413-812320202510.30712018

ANA - Agência Nacional de Águas e Saneamento Básico. Panorama do saneamento no Brasil. 2020. Disponível em: <https://www.ana.gov.br/saneamento/panorama-dosaneamento/panorama>. Acesso em: 12 out. 2020.

Araújo, A. C. B.; Pessoa, Z. S. Cidades sustentáveis e as políticas públicas urbanas: desafios na Região Metropolitana de Natal/RN. Anais do III ENEPCP - Encontro Nacional de Ensino e Pesquisa do Campo de Públicas, Natal, 2019.

ARCE - Agência Reguladora do Estado do Ceará. Relatório de fiscalização. Fortaleza: ARCE, 2020. Disponível em: <https://www.arce.ce.gov.br/relatorios-de-sistemas-deabastecimento-de-agua/>. Acesso em: 15 out. 2020.

Barreto, F. K. A. Inquérito soroepidemiológico de chikungunya e flavivírus (dengue e zika) e seus fatores associados na cidade de Juazeiro do Norte, Ceará, Brasil. Fortaleza: Universidade Federal do Ceará, 2020 (Tese de Doutorado).

Bartram, J.; Cairncross, S. Hygiene, Sanitation, and Water: Forgotten Foundations of Health. PLoS Medicine, v. 7, n. 11, e1000367, 2010. https://doi.org/10.1371/journal.pmed. 1000367

Borja, P. C. Política pública de saneamento básico: uma análise da recente experiência brasileira. Saúde e Sociedade, v. 23, p. 432-447, 2014. https://doi.org/10.1590/S010412902014000200007

Boyer, S.; Calvez, E.; Chouin-Carneiro, T.; Diallo, D.; Annabella, F. An overview of mosquito vectors of Zika virus. Microbes and Infection, v. 20, n. 11/12, p. 646-660, 2018. https://doi.org/10.1016/j.micinf.2018.01.006 
Brasil. Ministério da Saúde. Monitoramento dos casos de arboviroses urbanas transmitidas pelo Aedes aegypti (dengue, chikungunya e zika), semanas epidemiológicas 1 a 52, 2019. Brasília: Boletim epidemiológico; Ministério da Saúde, 2020a. Disponível em: <https://portalarquivos2.saude.gov.br/images/pdf/2020/ janeiro/20/Boletim-epidemiologico-SVS-02-1-pdf>. Acesso em: 03 nov. 2020.

Brasil. Ministério da Saúde. Monitoramento dos casos de arboviroses urbanas transmitidas pelo Aedes aegypti (dengue, chikungunya e zika), semanas epidemiológicas 1 a 36, 2020. Brasília: Boletim epidemiológico; Ministério da Saúde, 2020b. Disponível em: <https://antigo.saude.gov.br/images/pdf/2020/September/24/ Boletim-epidemiologico-SVS-38.pdf>. Acesso em: 14 out. 2020.

Campos, G. S.; Bandeira, A. C.; Sardi, S. I. Zika virus outbreak, Bahia, Brazil. Emerging Infectious Diseases, $\quad$ v. 21 , $\quad$ n. 10, p. 1885-1886, 2015. https://doi.org/10.3201/ eid2110.150847

Cao-Lormeau, V. M.; Blake, A.; Mons, S.; Lastère, S.; Roche, C.; Vanhomwegen, J.; Dub, T.; Baudouin, L.; Teissier, A.; Larre, P.; Vial, A.-L.; Decam, C.; Choumet, V.; Halstead, S. K.; Willison, H. J.; Musset, L.; Manuguerra, J.-C.; Despres, P.; Fournier, E.; Mallet, H.-P.; Musso, D.; Fontanet, A.; Neil, J.; Ghawché, F. Guillain-Barré Syndrome outbreak associated with Zika virus infection in French Polynesia: A case-control study. The Lancet, v. 387. n. 10027, p. 1483-1590, 2016. https://doi.org/10.1016/S0140-6736(16)00562-6

Cavalcanti, L. P. G.; Barreto, F. K. A.; Oliveira, R. M. A. B.; Canuto, I. F. P.; Lima, A. A. B.; Lima, J. W. O.; Escóssia, K. N. F.; Martins, V. E. P.; Alencar, C. H.; Perdigão, A. C. B.; Lima, D. M.; Ramalho, I. L. C.; Araújo, F. M. C. Trinta anos de dengue no Ceará: história, contribuições para a Ciência e desafios no cenário atual com tripla circulação de arbovírus. Journal of Health and Biological Sciences, v. 6, n. 1, p.65-82, 2018. https://doi.org/10.12662/ 2317-3076jhbs.v6i1.1415.p65-82.2018

Ceará. Secretaria das Cidades. Região Metropolitana do Cariri. Ceará, 2020a. Disponível em: <https://www.cidades.ce.gov.br/regiao-metropolitana-do-cariri/>. Acesso em: 06 out. 2020.

Ceará. Secretaria de Saúde do Estado do Ceará. Monitoramento dos casos de dengue, chikungunya e zika, semana epidemiológica 1 a 36, 2020. Ceará, CE. Boletim Epidemiológico: Arboviroses Urbanas, v. 36, 2020b. Disponível em: <https://www.saude.ce.gov.br/wp-content/uploads/sites/9/2018/06/boletim_ arboviroses_se36_10_set_2020-1.pdf>. Acesso em: 14 out. 2020.

Ceará. Secretaria de Saúde do Estado do Ceará. Monitoramento dos casos de dengue, chikungunya e zika, semana epidemiológica 1 a 44, 2020. Ceará, CE. Boletim Epidemiológico: Arboviroses Urbanas, v. 44, 2020c. Disponível em: <https://www.saude.ce.gov.br/wp-content/uploads/sites/9/2018/06/BOLETIM_ ARBOVIROSES_SE44_13_11_2020.pdf >. Acesso em: 21 nov. 2020.

Ceará. Secretaria de Saúde do Estado do Ceará. Boletim epidemiológico: arboviroses urbanas no 43/2019. Monitoramento dos casos de dengue, chikungunya e zika. Fortaleza, 2019. Disponível em: <https://www.saude.ce.gov.br/wp-content/uploads/ sites/9/2018/06/boletim_arbovirose_20_dezembro_2019.pdf>. Acesso em: 15 out. 2020.

Correia, M. L. A.; Dias, E. R. Desenvolvimento sustentável, crescimento econômico e o princípio da solidariedade intergeracional na perspectiva da justiça ambiental. Planeta Amazônia: Revista Internacional de Direito Ambiental e Políticas Públicas, n. 8, p. 6380, 2017. https://doi.org/10.18468/planetaamazonia.2016n8.p63-80 
Diniz, C. R.; Ferreira, W. B.; Fernandes, L. M. L.; Farias, H. Q.; Diniz, D. S. Aspectos do saneamento ambiental e arboviroses em municípios do cariri paraibano. Anais do 30ํㅡㄹ Congresso Brasileiro de Engenharia Sanitária e Ambiental, Natal, 2019. Disponível em: $<$ http://abes.locaweb.com.br/XP/XP-

EasyArtigos/Site/Uploads/Evento45/TrabalhosCompletosPDF/VII-046.pdf>. Acesso em: 12 out. 2020.

Djonú, P.; Rabelo, L. S. Lima, P. V. S.; Souto, M. V. S. Sabadia, J. A. B.; Sucupira Junior, P. R. G. Objetivos do Desenvolvimento Sustentável e condições de saúde em áreas de risco. Ambiente \& Sociedade, v. 21, e09110, 2018. https://doi.org/10.1590/18094422asoc0091r1vu1813td

Donalisio, M.; Freitas, A. Chikungunya no Brasil: um desafio emergente. Revista Brasileira de Epidemiologia, v. 18, n. 1, p. 283-285, 2015. https://doi.org/10.1590/19805497201500010022

Elmec, M. A.; Bataiero, M. O.; Cruz, M. G. B. Saneamento do meio, arboviroses e as estratégias de Vigilância Sanitária para combate aos vetores no Estado de São Paulo. Boletim Epidemiológico Paulista, v. 13, n. 153/154, p. 63-68, 2016.

Fairall, L.; Bateman, E. Health workers are vital to sustainable development goals and universal health coverage. British Medical Journal, v. 356, j1357, 2017. https://doi.org/10.1136/bmj.j1357

Fernandez, C. M. M.; Lorenzetti, F. B.; Lima, M. M. S.; Kleinubing, S. A.; Bortolucci, W. C.; Andrade, J. P. P.; Romagnolo, M. B.; Cortez, D. A. G.; Gazim, Z. C.; Dias Filho, B. P. Larvicidal activity of piperovatine and dichloromethane extract from Piper corcovadensis roots against mosquitoes Aedes aegypti L. Boletín Latinoamericano y del Caribe de Plantas Medicinales y Aromáticas, v. 19, n. 1, p. 142-148, 2020.

FUNASA - Fundação Nacional de Saúde. Impactos na saúde e no Sistema Único de Saúde decorrentes de agravos relacionados a um saneamento ambiental inadequado. Brasília: Fundação Nacional de Saúde, 2010.

Gil, L. H. S.; Katsuragawa, T. H.; Lima, A. A.; Tada, M. S.; Ozaki, L. S.; Julião, G. R. Rudimentary cesspits as breeding sites for Aedes aegypti in urban areas of Northern Brasil.

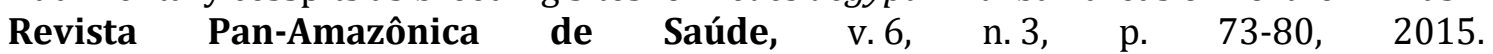
https://doi.org/10.5123/S2176-62232015000300010

Gouveia, N. Saúde e meio ambiente nas cidades: os desafios da saúde ambiental. Saúde e Sociedade, $\quad$ v. $8, \quad$ n. $1, \quad$ p. $49-61, \quad 1999 . \quad$ https://doi.org/10.1590/S010412901999000100005

Gundry, S.; Wright, J.; Conroy, R. A systematic review of the health outcomes related to household water quality in developing countries. Journal of Water and Health, v. 2, n. 1, p. 1-13, 2004. https://doi.org/10.2166/wh.2004.0001

Gusmão, C. M. G.; Patriota, A. C. D. L. S.; Carvalho, I. L. Aedes aegypti e arboviroses no Brasil. Revista Brasileira de Inovação Tecnológica em Saúde, v. 8, n. 3, p. 23, 2019. https://doi.org/10.18816/r-bits.v8i3.16340

Heller, L. Saneamento e saúde. Brasília: Organização Pan-Americana da Saúde, 1997.

Honório, N. A.; Câmara, D. C. P.; Calvet, G. A.; Brasil, P. Chikungunya: An arbovirus infection in the process of establishment and expansion in Brazil. Caderno de Saúde Pública, v. 31, n. 5, p. 906-908, 2015. https://doi.org/10.1590/0102-311XPE020515 
Hopwood, B.; Mellor, M.; O’Brien, G. Sustainable development: Mapping different $\begin{array}{lllll}\text { approaches. Sustainable Development, } & \text { v. 13, p. 38-52, } 2005 .\end{array}$ https://doi.org/10.1002/sd.244

IBGE - Instituto Brasileiro de Geografia e Estatística. Malha municipal. Rio de Janeiro: IBGE/Departamento de Recursos Naturais e Estudos Ambientais, 2018.

IBGE - Instituto Brasileiro de Geografia e Estatística. PNAD Contínua: abastecimento de água aumenta no Centro-Oeste em 2018, mas se mantém abaixo do patamar de 2016. 2019. Disponível em: <https://agenciadenoticias.ibge.gov.br/agencia-sala-deimprensa/2013-agencia-de-noticias/releases/24532-pnad-continua-abastecimento-deagua-aumenta-no-centro-oeste-em-2018-mas-se-mantem-abaixo-do-patamar-de-2016>. Acesso em: 12 out. 2020.

IBGE - Instituto Brasileiro de Geografia e Estatística. Censo demográfico 2010. Disponível em: <https://censo2010.ibge.gov.br>. Acesso em: 17 out. 2020.

IBGE - Instituto Brasileiro de Geografia e Estatística. Cidades IBGE. 2020. Disponível em: $<$ https://cidades.ibge.gov.br/>. Acesso em: 17 out. 2020.

IPEA - Instituto de Pesquisa Econômica Aplicada. ODS - Metas Nacionais dos Objetivos de Desenvolvimento Sustentável. Rio de Janeiro: IPEA, 2018. Disponível em: <http://www.ipea.gov.br/portal/images/stories/PDFs/livros/livros/180801_ods_metas_ nac_dos_obj_de_desenv_susten_propos_de_adequa.pdf>. Acesso em: 16 out. 2020.

IPECE - Instituto de Pesquisa e Estratégia Econômica do Ceará. Ceará em mapas. Fortaleza: IPECE, 2019.

IPECE - Instituto de Pesquisa e Estratégia Econômica do Ceará. Perfil municipal: Barbalha 2017. 2018a. Disponível em: <https://www.ipece.ce.gov.br/wp-content/uploads/ sites/45/2018/09/Barbalha_2017.pdf>. Acesso em: 15 out. 2020.

IPECE - Instituto de Pesquisa e Estratégia Econômica do Ceará. Perfil municipal: Crato 2017. 2018b Disponível em: <https://www.ipece.ce.gov.br/wp-content/uploads/ sites/45/2018/09/Crato_2017.pdf>. Acesso em: 15 out. 2020.

IPECE - Instituto de Pesquisa e Estratégia Econômica do Ceará. Perfil municipal: Juazeiro do Norte 2017. 2018c. Disponível em: <https://www.ipece.ce.gov.br/wp-content/ uploads/sites/45/2018/09/Juazeiro_do_Norte_2017.pdf>. Acesso em: 15 out. 2020.

Kjellstrom, T.; Friel, S.; Dixon, J.; Corvalan, C.; Rehfuess, E.; Campbell-lendrum, D.; Gore, F.; Bartram, J. Urban environmental health hazards and health equity. Journal of Urban Health, v. 84, Supl. 3, p. 86-97, 2007.

Lima Júnior, A. F. Análise espaço-temporal da dengue em Fortaleza e sua relação com o clima urbano e variáveis socioambientais. Fortaleza: Universidade Federal do Ceará, 2018. (Dissertação de mestrado).

Lowe, R.; Barcellos, C.; Brasil, P.; Cruz, O. G.; Honório, N. A.; Kuper, H.; Carvalho, M. S. The Zika virus epidemic in Brazil: From discovery to future implications. International Journal of Environmental Research and Public Health, v. 15, 1:96, 2018. https://doi.org/10.3390/ijerph15010096

Martins, A. B. S. Dengue no Ceará: 19 anos sob perspectiva espacial e temporal. Fortaleza: Universidade Federal do Ceará, 2020. (Dissertação de mestrado).

Mendonça, F. A.; Souza, A. V.; Dutra, D. A. Saúde pública, urbanização e dengue no Brasil. Sociedade \& Natureza, v. 21, n. 3, p. 257-269, 2009. https://doi.org/10.1590/S198245132009000300003 
Moe, C.; Rheingans, R. Global challenges in water, sanitation and health. Journal of Water and Health, v. 4, Supl. 1, p. 41-57, 2006. https://doi.org/10.2166/wh.2006.0043

Moreira, P. P. T. Diagnóstico urbano da infraestrutura de saneamento básico da Cidade de Anápolis, GO: subsídios para políticas públicas. Anápolis: Centro Universitário Unievangélica, 2015. (Dissertação de mestrado).

Nascimento, D. C.; Chacon, S. S. Sustentabilidade na Região Metropolitana do Cariri - RMC: análise a partir dos objetivos de desenvolvimento do milênio - ODMs. Sociedade \& Natureza, v. 28, n. 3, p. 443-456, 2016. https://doi.org/10.1590/1982-451320160309

Ndeffo-Mbah, M. L.; Parpia, A. S.; Galvani, A. P. Mitigating prenatal Zika virus infection in the Americas. Annals of Internal Medicine, v. 165, n. 8, p. 551-559, 2016. https://doi.org/10.7326/M16-0919

Oliveira Júnior, A. A água potável nos Objetivos de Desenvolvimento Sustentável (ODS): um olhar do setor saúde. Brasília: Universidade de Brasília, 2018. (Dissertação de mestrado).

ONU - Nações Unidas Brasil. Objetivos de desenvolvimento sustentável. 2020. Disponível em: <https://brasil.un.org/pt-br>. Acesso em: 15 out. 2020.

Pereira, C. E.; Cardoso, P. H. G. Contribuição das Instituições de Ensino Superior no processo de crescimento e desenvolvimento da Região Metropolitana do Cariri, Ceará, Brasil. Research, Society and Development, v. 9, n. 3, p. 1-20, 2020. https://doi.org/10.33448/rsd-v9i3.2531

Rossetto, E. V.; Angerami, R. N.; Luna, E. J. A. What to expect from the 2017 yellow fever outbreak in Brazil? Revista do Instituto de Medicina Tropical, v. 59, e17, 2017. https://doi.org/10.1590/s1678-9946201759017

Sachs, J. D. From millennium development goals to sustainable development goals. The Lancet, v. 379, n. 9832, p. 2206-2211, 2012. https://doi.org/10.1016/S01406736(12)60685-0

San Pedro, A.; Souza-Santos, R.; Sabroza, P. C.; Oliveira, R. M. Condições particulares de produção e reprodução da dengue em nível local: estudo de Itaipu, Região Oceânica de Niterói, Rio de Janeiro, Brasil. Cadernos de Saúde Pública, v. 25, n. 9, p. 1937-1946, 2009. https://doi.org/10.1590/S0102-311X2009000900008

Sena, A.; Freitas, C. M.; Barcellos, C.; Ramalho, W.; Corvalan, C. Medindo o invisível: análise dos Objetivos de Desenvolvimento Sustentável em populações expostas à seca. Ciência \& Saúde Coletiva, v. 21, n. 3, p. 671-683, 2016. https://doi.org/10.1590/141381232015213.21642015

Silva, E. Reprodução do Aedes aegypti em fossas de esgotamento sanitário no Bairro dos Pioneiros, zona urbana de Pimenta Bueno - Rondônia, Amazônia Ocidental. Brasília: Universidade de Brasília, 2007. (Dissertação de mestrado).

Silva, J. C. B.; Machado, C. J. S. Associações entre dengue e variáveis socioambientais nas capitais do Nordeste brasileiro por análise de agrupamentos. Ambiente \& Sociedade, v. 21, e01332, 2018. https://doi.org/10.1590/1809-4422asoc0133r2vu1814td

Teixeira, M. D. G.; Barreto, M. L.; Guerra, Z. Epidemiologia e medidas de prevenção do Dengue. Informe Epidemiológico do SUS, v. 8, $\quad$ n. 4, $\quad$ p. 5-33, 1999. https://doi.org/10.5123/S0104-16731999000400002 
Teixeira, M. G.; Barreto, M. L. Porque devemos, de novo, erradicar o Aedes aegypti. Ciência \& Saúde Coletiva, v. 1 , n. 1, p. 122-136, 1996. https://doi.org/10.1590/1413812319961101582014

Torii, S.; Orba, Y.; Sasaki, M.; Tabata, K.; Wada, Y.; Carr, M.; Hobson-Peters, J.; Hall, R. A.; Takada, A.; Fukuhara, T.; Matsuura, Y.; Hall, W. W.; Sawa, H. Host ESCRT factors are recruited during chikungunya virus infection and are required for the intracellular viral replication cycle. Journal of Biological Chemistry, v. 295, n. 23, p. 7941-7957, 2020. https://doi.org/10.1074/jbc.RA119.012303

UN - United Nations. World urbanization prospects: The 2019 revision. 2018. Disponível em: <https://population.un.org/wup/Publications/Files/WUP2018-Report.pdf>. Acesso em: 10 out. 2020.

UNDP - Programa das Nações Unidas para o Desenvolvimento. Transformando o nosso mundo: a agenda 2030 para o desenvolvimento sustentável. Nova Iorque: UNDP, 2016. Disponível em: <https://www.undp.org/content/dam/brazil/docs/agenda2030/undp-brAgenda2030-completo-pt-br-2016.pdf>. Acesso em: 10 out. 2020.

UNSDSN - United Nations Sustainable Development Solutions Network. Índice e painel preliminar dos Objetivos de Desenvolvimento Sustentável (ODS). 2016. Disponível em: <http://unsdsn.org/wp-content/uploads/2016/02/160308--\%C3\%8Dndice-e-PainelPreliminar-dos-ODS-pt.pdf>. Acesso em: 14 out. 2020.

Vianna, A. M. Poluição ambiental: um problema de urbanização e crescimento desordenado das cidades. Revista Sustinere, v. 3, n. 1, p. 22-42, 2015. https://doi.org/10.12957/sustinere.2015.17325

Wilder-Smith, A.; Ooi, E.; Horstick, O.; Wills, B. Dengue. The Lancet, v. 393, p. 350-363, 2019. https://doi.org/10.1016/S0140-6736(18)32560-1

WHO - World Health Organization. World urbanization prospects: The 2007 Revision. New York: WHO, 2008.

WHO - World Health Organization. Handbook for clinical management of dengue. Geneva: WHO, 2012.

Yang, D.; He, Y.; Ni, W.; Lai, Q.; Yang, Y.; Xie, J.; Zhu, T.; Zhou, G.; Zheng, X. Semi-field lifetable studies of Aedes albopictus (Diptera: Culicidae) in Guangzhou, China. PLoS ONE, v. 15, n. 3, e0229829, 2020. https://doi.org/10.1371/journal.pone.0229829

Zanon, L. H. Saneamento básico e sua interferência na saúde pública com enfoque na proliferação do Aedes aegypti. Medianeira: Universidade Tecnológica Federal do Paraná, 2018. (Monografia de Especialização).

Zara, A. L. S. A.; Santos, S. M.; Fernandes-Oliveira, E. S.; Carvalho, R. G.; Coelho, G. E. Estratégias de controle do Aedes aegypti: uma revisão. Epidemiologia e Serviço de $\begin{array}{lllll}\text { Saúde, } & \text { v. } 25, & \text { n. } 2, & \text { p. 391-404, 2016. https://doi.org/10.5123/S1679- }\end{array}$ 49742016000200017

Informação da Licença: Este é um artigo Open Access distribuído sob os termos da Licença Creative Commons Attribution, que permite uso irrestrito, distribuição e reprodução em qualquer meio, desde que a obra original seja devidamente citada. 